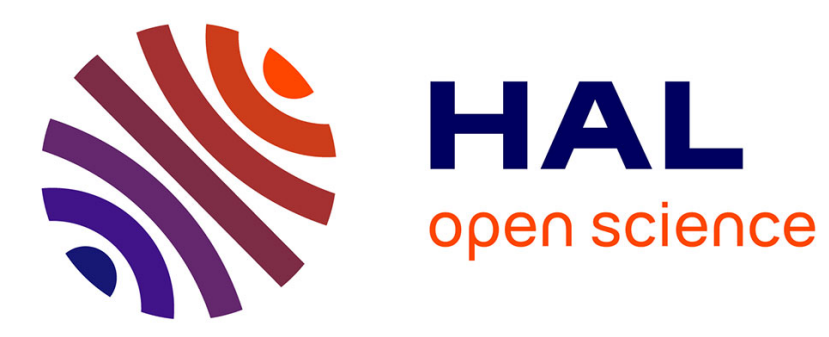

\title{
Language Revitalization
}

\author{
Aidan Pine, Mark Turin
}

\section{To cite this version:}

Aidan Pine, Mark Turin. Language Revitalization. Oxford research encyclopedia of linguistics, Oxford University Press, 2017, 10.1093/acrefore/9780199384655.013.8 . halshs-03083360

\section{HAL Id: halshs-03083360 https://shs.hal.science/halshs-03083360}

Submitted on 27 Jan 2021

HAL is a multi-disciplinary open access archive for the deposit and dissemination of scientific research documents, whether they are published or not. The documents may come from teaching and research institutions in France or abroad, or from public or private research centers.
L'archive ouverte pluridisciplinaire HAL, est destinée au dépôt et à la diffusion de documents scientifiques de niveau recherche, publiés ou non, émanant des établissements d'enseignement et de recherche français ou étrangers, des laboratoires publics ou privés. 


\section{Oxford Research Encyclopedia of Linguistics}

\section{Language Revitalization}

Aidan Pine and Mark Turin

Subject: Applied Linguistics, Historical Linguistics, Language Families/Areas/Contact, Psycholinguistics Online Publication Date: Mar 2017

DOI: $10.1093 /$ acrefore/9780199384655.013.8

\section{Summary and Keywords}

The world is home to an extraordinary level of linguistic diversity, with roughly 7,000 languages currently spoken and signed. Yet this diversity is highly unstable and is being rapidly eroded through a series of complex and interrelated processes that result in or lead to language loss. The combination of monolingualism and networks of global trade languages that are increasingly technologized have led to over half of the world's population speaking one of only 13 languages. Such linguistic homogenization leaves in its wake a linguistic landscape that is increasingly endangered.

A wide range of factors contribute to language loss and attrition. While some-such as natural disasters - are unique to particular language communities and specific geographical regions, many have similar origins and are common across endangered language communities around the globe. The harmful legacy of colonization and the enduring impact of disenfranchising policies relating to Indigenous and minority languages are at the heart of language attrition from New Zealand to Hawai'i, and from Canada to Nepal.

Language loss does not occur in isolation, nor is it inevitable or in any way "natural." The process also has wide-ranging social and economic repercussions for the language communities in question. Language is so heavily intertwined with cultural knowledge and political identity that speech forms often serve as meaningful indicators of a community's vitality and social well-being. More than ever before, there are vigorous and collaborative efforts underway to reverse the trend of language loss and to reclaim and revitalize endangered languages. Such approaches vary significantly, from making use of digital technologies in order to engage individual and younger learners to community-oriented language nests and immersion programs. Drawing on diverse techniques and communities, the question of measuring the success of language revitalization programs has driven research forward in the areas of statistical assessments of linguistic diversity, endangerment, and vulnerability. Current efforts are re-evaluating the established triad of documentation-conservation-revitalization in favor of more unified, holistic, and community-led approaches.

Keywords: endangered, revitalization, resurgence, colonization, globalization, technology, Indigenous, British Columbia, Hawai’i, Māori

\section{Introduction}

To make sense of the many varied paths that language revitalization is taking across the globe, it is necessary to first contextualize the root causes of language endangerment. The very use of the prefix 're' in words such as revitalization, rejuvenation, revival, and resurgence points to 
the undoing of some past action or deed (Glass, 2004). Namely, if the world's linguistic diversity had not been "devitalized" to begin withthrough colonization, imperial adventure, war, and forced migration - there would be less need for historically marginalized languages with ever-dwindling numbers of speakers to be "revitalized" today. The work of language revitalization is inherently multidisciplinary and very often political, with long-range cultural and social goals that extend beyond the immediate task of generating more speakers. Through illustrative examples and case studies from British Columbia, Hawai' 1 , and Aotearoa (New Zealand), this contribution demonstrates that language revitalization programs are as much focused on decolonizing education and plotting a path toward self-determination as they are directed at reclaiming grammar and speech forms.

More nuanced techniques for evaluating progress and success in language revitalization efforts have emerged from a deeper understanding of the distinct goals of individual revitalization projects. Methods include quantitative scales backed by international non-governmental organizations, tracking and status reports on linguistic vitality and speaker numbers from governmental organizations as well as broader social scientific investigations into correlations between community health, well-being, and language vitality. The next steps will involve developing evaluative criteria that are grounded in local understandings of impact and success, rooted in the lived experiences and aspirations of Indigenous communities. Language revitalization, driven by the crisis of language endangerment, is a dynamic subfield experiencing rapid growth, with the roles and responsibilities of the various stakeholders in considerable flux. Through an inclusive understanding of the sociopolitical, historical, Indigenous, ${ }^{1}$ and academic contexts that shape language revitalization projects, collaborative and productive relationships between language communities, governments, and academics are emerging, breathing renewed life into historically marginalized languages across the globe.

\section{Marginalization and Devitalization of Language}

\subsection{Sociopolitical Context and Colonial Policy}

Statistics and enumeration aside, endangered languages and the communities that speak them are under extreme stress. Even conservative estimates paint a picture of near-catastrophic endangerment levels, with half of the world's remaining speech forms ceasing to be used as everyday vernaculars by the end of the 21 st century (Krauss, 1992). The pressures facing endangered languages are as severe as those recorded by conservation biologists for flora and fauna, and in many cases more acute (Sutherland, 2003). Yet linguistic endangerment is by no means a natural or inevitable process, the unfortunate by-product of modernization. Rather, the marginalization and erosion of local and Indigenous languages is the direct result of colonization and the racist policies that accompanied it. Across the world and through a variety of efforts that have included education initiatives, punitive legislation, and intentional neglect, colonial authorities have instituted language policies that sought to weaken traditional cultural ways, assimilate Indigenous populations, and gain access to their land and resources.

Conscious that "language is the perfect instrument of empire" (Morris, 2003, p. 103), the architects of colonial advancement were highly effective in using language to underwrite the success of their imperial ventures. Although Indian residential schools in Canada, American Indian boarding schools in the United States, native schools for Māori in New Zealand, and Christian missionary schools in Hawai'i were governed and shaped by diverse motivations, they were united by a prejudiced belief that Indigenous languages were backward, primitive, and incompatible with modernity and Western values. Richard Henry Pratt (1840-1924), founder and long-time superintendent of the influential Carlisle Indian Industrial School in Pennsylvania, summed up this prevailing sentiment when he pugnaciously proposed that the government must "kill the Indian ... to save the man." In such schools, the goal was for English (or another colonizing language such as French, Spanish, or Portuguese) to overwrite local languages and for Western Christianity to supplant Indigenous belief systems and traditional ways, thus forcing the dislocation of Indigenous peoples from their land, territories, and systems of traditional knowledge and governance. Colonization did not always come from the outside or lead to permanent settlement; some nations were internally colonized and then subjugated by their own elites, who then advanced, as in the case of Nepal, a single state-sponsored language and religion in the name of unification and nation building (Turin, 2006).

Colonial authorities used the power of language and the language of power to further their own strategic ends. In some cases, and seemingly paradoxically, this involved supporting Indigenous languages; in most cases, however, they sought to erode them. In the first instance, believing 
in the inherent superiority of Christian theology, many missionary linguists focused on translating scripture into Indigenous languages. In Papua New Guinea and other regions of the Asia Pacific, scholars and administrators actively strengthened Indigenous languages through standardization programs that involved grammatical descriptions and the compilation of dictionaries and other pedagogical tools (Wurm, Muehlheausler, \& Laycock, 1977). The goal_in many cases — was for local languages to be harnessed to transmit and disseminate an imagined Christian modernity. In other instances, as in Canada, settler-colonial authorities observed the unique relationship that existed between a language and the land on which it was spoken and focused their attention on breaking this apart by destroying the language and forcibly relocating communities far away from their traditional territories.

To this day, Indigenous communities around the world make use of traditional place names to ascribe current or historical meaning to places and spaces that are locally resonant and historically important. Such toponyms often encode lived experience and traditional ecological knowledge in an ancestral language in a way that is almost impossible to translate into a more dominant national or international language. By disconnecting the language traditionally used to refer to a specific site, and by introducing new place names in a colonial language (the terms "New Zealand" and "British Columbia" serve as enduring examples), the relationship that local peoples have with their land was rendered more opaque and attenuated. Having weakened this connection to land, the colonial goal of relocating communities in order to extract resources from their territories became more achievable.

In the 1800s, a range of legislative provisions were introduced throughout the colonized world that sought to justify colonial expansion through the advancement of colonial languages. Passed in 1835, the English Education Act required that all government funding for education and literature in British India be dedicated to the development of the English language, diverting resources away from critical and widely used languages such as Sanskrit, Persian, and Arabic, which had been previously supported. The tabling of this Act reflects a wider imperial linguistic agenda that would have long-lasting implications across the world. Politician and historian Thomas Babington Macaulay (1800-1859) lent his name to the now infamous "Macaulay Minute" in which he asserted that it was "no exaggeration to say that all the historical information which has been collected from all the books written in the Sanskrit language is less valuable than what may be found in the most paltry abridgement used at preparatory schools in England" (Macaulay, 1835). By the middle of the 19th century, the educational goals of the British empire had solidified: an education administered in English was understood to be inherently superior to any training, understanding or knowledge that could be derived from another language, particularly languages spoken beyond the boundaries of Western Europe. The formalization of this formulation had an immediate and devastating impact on Indigenous languages across the colonized globe: the Canadian residential school system was established soon after, in the 1840s, while in New Zealand, the Native Schools Act mandated an English-only approach to education starting in 1867 (Simon \& Smith, 2001). Beneath the thin veil of education and "civilization," such schools were a means to eliminate Indigenous communities as obstacles to land acquisition, resource extraction, and nation building (Woolford, 2015).

Yet, for as long as efforts have existed to impose colonial languages on Indigenous peoples as a means of reshaping their identity, these same processes have been vigorously opposed by speakers of these languages. Anti-colonial opposition to externally imposed language policy takes many forms, from active resistance to passive non-compliance. Everyday forms of resistance have included the direct avoidance of colonial education programs by concealing children and evading census enumerators to more contemporary and structured efforts at language revitalization and reclamation. The emergence of the Caribbean linguistic mosaic can be seen as an anti-colonial response predicated on "the need to speak and not be understood by the downpressors (slave masters, elite of society)" (Barcant, 2013, p. 51). Viewed in this light, the creation of a patois/patwah or creole/kweyol can be read as a linguistic manifestation of a moral objection to the imposition of a hegemonic identity advanced by an imperial state, a perspective further substantiated by the Métis of Canada, who "moulded the aboriginal and settler languages into coherent patterns which reflected their own cultural and historical circumstances" (Michif Languages Conference, 1985).

The long march toward decolonization continues. In 2015, the Truth \& Reconciliation Commission of Canada (TRC) released its report detailing the history of Indigenous peoples' lived experiences through the nation's residential school period that lasted from 1883 to the late 1990s. The TRC heard over 6,000 testimonies and affirmed that "[t]hese residential schools were created for the purpose of separating Aboriginal children from their families, in order to minimize and weaken family ties and cultural linkages" (Truth and Reconciliation Commission of Canada, 2015). Noting the many brutal and dehumanizing mechanisms that supported, funded, and sanctioned the institutionalized neglect of Aboriginal children, the TRC proposed a list of recommendations and calls to action that would set Canada on a path 
to reconciliation for the terrible wrongs committed during this period. Relevant to language revitalization are clear suggestions and proposals on how to shape a national language policy in a manner that would address the impact of over 100 years of language policy that prohibited and punished the use of Indigenous languages in residential schools. The TRC report offers five tangible recommendations that include the creation of an Aboriginal Languages Act, the introduction of an Aboriginal Languages Commissioner at the federal level of government, and an acknowledgment that Aboriginal rights include rights to speak and preserve Indigenous languages. Under the leadership of Prime Minister Justin Trudeau, the government of Canada has pledged to implement each point in the TRC's Calls to Action (Statement by Prime Minister, 2015). While Canada is internationally celebrated for its official language policy in which French and English-both languages introduced by colonial settlers - are placed on an equal footing, it is worth noting that not a single language Indigenous to Canada has "received" national recognition.

Overall, to make sense of contemporary efforts to revitalize Indigenous languages, it is essential to understand the political and historical context that has shaped their marginalization. Revitalization would not be needed had these languages not been asphyxiated to begin with. The growing recognition of the legacy of colonial oppression of Indigenous languages has also motivated a realignment of the discourse around language endangerment. The majority of languages spoken across the world have endured punitive policies that actively sought to eradicate them. Their continued use to this day - even if only by a handful of speakers in some cases - is indicative of the resilience of communities in the face of continued oppression. Commonly used terms that highlight the "endangered-ness" of a language - we may think of words such as "weak," "loss," and even the word "endangered" itself-overrepresent diminishment and underrepresent the resurgent strength of communities of speakers who have never stopped using their ancestral languages. Furthermore, the currency of terms such as "vanishing" and "disappearing" not only forecloses the possibility of revival and renewal but communicates an apparently agentless process in which language loss is both inevitable and naturally occurring. Such terminology both effaces the intentionality of colonial policies that legislated marginalization and undermines the efforts of those working to reclaim their languages. When speaking and writing of "endangered languages," then, it is crucial to remain attentive to the words that are used and to seek balance in highlighting ongoing community revitalization efforts on the one hand, while historically contextualizing the increasingly vulnerable state of most Indigenous languages on the other.

\subsection{Measuring Language Endangerment, Revitalization, and the Effects of Language Loss}

As strategies for language revitalization deepen and widen, the techniques used to evaluate success and impact must become both more grounded in community goals and better informed by analytical rigor. The urgency of the work of language revitalization further requires that communities be expedient and efficient in their application and choices, a process that can be aided through robust and comparative data. Language communities are in the best position to identify the language revitalization-related questions that they need research to answer, and care must be taken to avoid positioning them as competitors with universities for funding resources and visibility.

A widely used and highly regarded method for gauging the status and prospects of a language is the UNESCO Language Vitality Assessment (Figure 1; Brenzinger et al., 2003). This tool advances a holistic approach for measuring linguistic vitality that draws on multiple elements, since "no single factor alone can be used to assess a language's vitality or its need for documentation" (Brenzinger et al., 2003, p. 7).

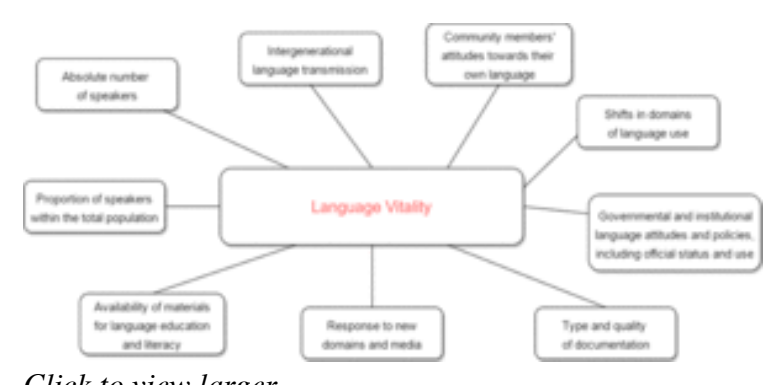

Click to view larger

Figure 1. A visual representation based on the UNESCO Language Vitality Assessment (from Brenzinger et al., 2003).
In this assessment, nine factors are evaluated on a 5-point scale, with the exception of the second component, which records the absolute number of speakers. The UNESCO approach does not advocate an even weighting across all indicators and rather proposes that elements should be weighted according to local community norms. While this assessment tool provides an accurate snapshot of the overall health of a language, its adjustable framework makes it harder to compare vitality - and in turn language revitalization programs - cross-linguistically.

The 13-stage Expanded Graded Intergenerational Disruption Scale (EGIDS) (Lewis \& Simons, 2010), used by the popular if historically problematic Ethnologue (Dobrin, 2009), offers a standardized approach for evaluating the vitality of a language that 
allows for simple comparisons with other languages spoken and signed around the world. The scale ranges from 0 (International) to 10 (Extinct) and is often portrayed as in Figure 2, where the $x$-axis represents the EGIDS level, the $y$-axis represents native speaker population, and the plotted points represent individual languages. Through a search function on the Ethnologue website, individual languages can be highlighted on the graph.

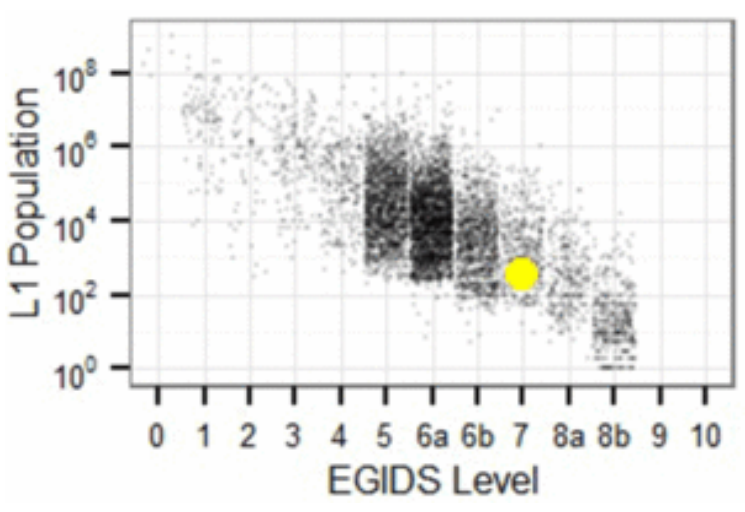

Click to view larger

Figure 2. An EGIDS graph with the yellow dot showing Gitksan (Tsimshianic) (from Lewis, Simons, \& Fennig, 2016).

impact on the lives and livelihoods of Indigenous communities.

Accordingly, the question of what constitutes "successful" language revitalization may need to be re-evaluated (Hinton, 2015). Conventionally, the absolute number of fluent speakers of a language remains the most discernible factor that is tracked and measured, but language revitalization projects that focus on creating a cultural context for more semi-speakers can have equally important and lasting impact. Community-led language revitalization projects that prioritize youth engagement with traditional cultural and environmental knowledge may be as much focussed on sustainable well-being as they are on grammar, words, and orthographies.

Honesty about what counts as success and how it can be measured is an important aspect of planning a language revitalization project and can also help to guide curricular decisions in the classroom. The structure of any language revitalization program must be driven by the goals of the language community in question. Only once these are discussed and articulated, through a process of community-directed planning and consultation, can appropriate evaluative metrics be developed. The Mentor-Apprentice program focuses on bringing dedicated individual learners to a high level of fluency through intensive exposure to their ancestral language in whatever way is most culturally salient and appropriate. This effective and intentionally small-scale, personalized, and grassroots approach embodies the belief that language revitalization happens one speaker at a time (Hinton, 2001B). Since its inception in 1992 by the Native California Network (Hinton, 2001 B, p. 219), the Master-Apprentice (and later Mentor-Apprentice) program has spread across the United States as well as internationally in Australia (Olawsky, 2013) and Finland (Olthuis, Kivelä, \& Skutnabb-Kangas, 2013).

Inspired by the Mentor-Apprentice program and by accessible handbooks such as Bringing Our Languages Home: Language Revitalization for Families (Hinton, 2013), written for a community audience, speakers and learners have felt empowered to bring ancestral languages back into their lives. Organizations such as the First People's Cultural Council (FPCC) in British Columbia provide funding and administrative support for Mentor-Apprentice partnerships, helping to alleviate some of the financial burden associated with the substantial commitment of time and resources that such partnerships require. Whether highly structured and systematic, or informal and community-directed, Mentor-Apprentice programs assume a definition of success that is predicated on an individual learner's ability to become proficient and ultimately fluent in a language. It should be noted that resource intensive Mentor-Apprentice programs focussed on individual partnerships can be antithetical to the mandates of policy makers and governmental granting bodies, whose funding modalities are usually driven by a conviction that impact can be maximized by ensuring the widest possible access. 
With language revitalization increasingly situated as an expression of self-determination and political empowerment, some language communities are developing a terminology for discussing endangerment and revitalization that is in itself empowering. One example is a movement to refer to languages without any current L1 (native or first-language) speakers as "sleeping" rather than "extinct" (Hinton, 2001 A). While the distinction might appear unnecessary or even naively aspirational to researchers not closely involved in such work, all terminology has both symbolic value and political impact. The biological extinction of a species has a mono-directional finality that linguistic "extinction" does not. As Indigenous linguist Wesley Leonard poignantly notes, "the paradox of speaking an extinct language is not imaginary" (2008, p. 28). The designation "sleeping" rather than "extinct" points to the potential of a language to be reclaimed and revived after it has lost its remaining L1 speakers - an opportunity that is not available to the dodo or a dinosaur. While bringing a language back from sleeping to having a community of fluent speakers is a phenomenon that has been uncommon in human history, there are recent examples, such as the remarkable and compelling case of the Wampanoag (Algonquin) language, which was sleeping from the late 19th century until revitalization efforts resulted in fluent child speakers of the language in the 21st century (Makepeace, 2010).

When active language planning and restoration is effective, as in the case of the development of modern spoken Hebrew following the establishment of the state of Israel, it is often the result of a combination of historical motivation, political self-determination, cultural revival, and community mobilization. Even so, there are notable characteristics that appear unique to languages that undergo a successful transition from sleeping to awake. This is certainly the case with modern spoken Hebrew, which "is based simultaneously on 'sleeping beauty' / 'walking dead' Hebrew and 'máme lóshn' (mother tongue) Yiddish, which are both primary contributors to Israeli, and a plethora of other tongues spoken by Jewish pioneers in Palestine in the 1880s-1930s, e.g. Russian, Polish, Arabic, Ladino (Judeo-Spanish), Turkish, German, French and English" (Zuckermann \& Walsh, 2011, p. 114). Even in the event that a language is effectively revitalized, the resulting speech form will inevitably have been shaped by language contact and by the mother tongue of the revitalizers themselves. In some cases there is resistance to such adaptation within speech communities: elders may find it hard to accept a new and changed linguistic reality, perceiving the revived language to be a hybrid amalgam or simply incorrect. Linguistic authenticity remains a pervasive notion in which "the supposed ideal is intergenerational transmission of the language with all its original structural complexity retained, thus creating unrealistic expectations among the Aboriginal community" (Zuckermann \& Walsh, 2011, p. 113). While the achievement of establishing modern Hebrew is beyond doubt (Spolsky, 1995), it is by no means the only effective language revitalization effort. For peoples like the Myaamia (Algonquin), who have no first language speakers left, "the ultimate goal of this work is to eventually be able to raise our children with the beliefs and values that draw from our traditional foundation and to utilize our language as a means of preserving and expressing these elements" (Baldwin, 2003, p. 28). Rather than some ideal, end-state fluency, it is the sustained effort of communities that shape and determine the goal and success of any language revitalization project. As all who are engaged in language revitalization can attest, the work is never complete: success starts when revitalization efforts begin and doesn't end until efforts themselves cease (Hinton, 2015).

\section{Language Revitalization: Goals and Examples}

As a practice, language revitalization takes many shapes. Some of the earliest language activists were the children and students who, risking corporal or psychological punishment, continued to speak their languages in residential and boarding schools and at home with their families. Since the retraction of explicit bans on speaking Indigenous languages in public in many countries, some of which have only been lifted within the last few decades (Anchimbe, 2006; Bulcha, 1997), language revitalization has become noticeably less subversive. Many language revitalization programs now receive support from band councils, non-governmental organizations, philanthropic foundations, and even governmental bodies and programs.

Much of the language activism witnessed in the mid-to-late 20th century in Anglo settler-colonial contexts such as Canada, the United States, and Australia focused on the development of orthographies (writing systems) and lexicography (dictionary compilation) projects. While the latter continues, the former-at least in Canada and the United States - is now mostly complete, although substantial disagreements exist within speech communities who may be divided by competing writing systems (see Hinton, 2014). There are notable exceptions to the historical trajectory outlined above. The Māori have made good use of a practical orthography since the early 19th century; the Canadian syllabary for 
Algonquian, Inuit, and Athabaskan languages was in active use from the mid-18th century; and the Cherokee syllabary developed by Sequoyah (ca. 1770-1843) has been used from the very early 19th century. Developing and standardizing practical writing systems continues to be a central focus for many recent language revitalization projects across South Asia, Africa, and Oceania, where a vast number of Indigenous languages are still spoken and the structures and patterns of colonial government were quite different from North America and Australia, leading to distinct post-colonial legacies.

In continental North America, following the development of orthographies, beginner dictionaries became the focus for many language revitalization initiatives, alongside the introduction of teaching curriculum for a number of languages including Gitksan (Tsimshianic), Kwak’wala (Wakashan), Inuktitut (Inuit), and Cree (Algonquin) (Barnett, Seymour, \& Raine, 1975; Cree Productions, 1973; Jensen \& Powell, 1979; Kativik School Board, 1979; Powell, Cook, Cranmer, \& Jensen, 1981). In parallel, immersion schools and language nests were becoming the focus of Indigenous revitalization movements elsewhere, including the pünana leo in Hawai'i (Watson-Gegeo, 1989) and köhanga reo in Aotearoa (also known as New Zealand) (Hohepa, 1984), from which the English term "language nest" derives. Since the 1980s, the visibility and impact of the Hawaiian and Māori initiatives have inspired other language nest-style immersive language programs around the world.

Initiated as a response to concerns that Māori youth had inadequate exposure to their language through the growing dominance of English, the kōhanga reo program sought to provide an immersive environment for Māori children to gain early exposure to, and receive education in, Māori. Over 450 kōhanga reo programs have been established throughout Aotearoa serving children from birth to age six. There has been a significant drop in enrollment since a peak in the 1990s. In 1996, 46.3\% of Maori children were enrolled in kôhanga reo as compared to only 20.4\% in 2009 (Statistics New Zealand "Maori: Growth in early childhood education," 1996; New Zealand Childcare Survey, 2010). While this drop is of concern to many language activists in Aotearoa and beyond, it still represents an unparalleled level of access that Māori children have to immersive Māori language early childhood education as compared with the opportunities available for speakers of other endangered languages.

Building on the success of the pre-school kōhanga reo programs, primary (kura kaupapa Māori), secondary (kura tuarua), and post-secondary (wananga) Māori immersion school programs were developed, all of which support Māori community members in accessing a comprehensive education shaped by Indigenous Māori cultural and linguistic values (Hingangaroa Smith, 2003). Part of the success in implementing this integrated program for so many students across all ages, aside from the unflagging dedication and commitment of the Māori people themselves, can be attributed to the wider geographical and linguistic landscape of the region in which Māori is spoken. Māori is the principal Indigenous language of Aotearoa (a number of other languages are spoken outside of the main islands, such as Penrhyn [Tahitic]), and standardization occurred relatively early. The result is that curricula and legislative efforts have been concentrated in a way that is hard to imagine in linguistically diverse regions like California or British Columbia, let alone resource-strapped Nepal or Papua New Guinea. The reduced linguistic diversity that is more common in island-states appears to provide a strategic advantage for revitalization efforts in terms of resource allocation and perceived impact.

In some language communities where orthographies have either not been standardized or remain in dispute, revitalization strategies prioritize spoken competence and oral transmission over classroom instruction that focuses on writing and texts. The Accelerated Second Language Acquisition (ASLA) method, developed by Dr. Stephen Greymorning, encourages learners to rely on visual and pragmatic cues to learn language and is particularly popular among Indigenous communities in North America. Similarly, the Where Are Your Keys (WAYK) method has been used widely and combines various gestures and techniques to keep learners communicative without relying on using English or their mother tongue. The WAYK technique has been used by Indigenous language communities across Canada and the United States, including Unangam Tunuu (Aleut), and even for spoken Latin.

Influenced by the success of kōhanga reo in Aotearoa, the Secwepmec (Salish) community of Adams Lake founded the Chief Atahm Immersion School in 1991. The school offers immersion programs for children (birth to age five), part-time language classes for grades four to nine, and community language classes for adults. The Chief Atahm Immersion School makes use of a technique known as Total Physical Response (TPR), which relies heavily on somatosensory stimulation to promote language learning. Chief Atahm Immersion School is the first Indigenous language immersion school in British Columbia, but not the first in Canada, with the Mohawk (Iroquoian) language immersion program in 
Kahnawake, Quebec, dating to 1979. The Mohawk program took its cue from French language immersion programs which were gaining momentum in the 1970s as a part of Quebec's assertion of a Francophone identity. While impressive and certainly effective, immersion programs are not one-way tickets to native levels of fluency. Immersion programs operate best when there are sufficient extracurricular environments in which students can interact in and use the language during play and everyday communication. The dominance of English in the wider environment that surrounds many immersion programs often affects a learner's ability and desire to speak the language outside of the immersion setting and can even influence a learner's acquisition of the immersion language. Preliminary research demonstrated that a learner at Chief Atahm School was overregularizing her use of independent pronouns in Secwepemctsin (a polysynthetic language) under the influence of her extracurricular exposure to English (Lai \& Ignace, 1998).

Other grassroots language reclamation programs have few resources and no formal support. Every day, across the world, informal classes and gatherings at homes, community halls, churches, and schools bring together people who are interested in learning or relearning their languages. Sometimes these programs are taught by L1 speakers, while other times they are led by very committed student learners or semi-fluent speakers. Combining a mixture of curriculum developed by the Paul Creek Language Association and Darrell Kipp's controversial advice about language revitalization, ${ }^{2}$ language activist and educator Michelle K. Johnson, together with four dedicated students, created their own immersion class. For five months, located at a remote site along the Canada/U.S. border, they spent a strict eight hours per day immersed in the Nsylxcin language (Salish), including 20 hours a week of active curriculum learning (Johnson, 2012). According to levels set by the American Council on the Teaching of Foreign Languages, after emerging from this intense and intensive form of immersion, each of the learners had progressed from being a complete non-speaker to attaining a low-intermediate conversational level. While the Nsylxcin immersion program was intentionally more vigorous than most grassroots community language revitalization initiatives can afford to be, it represents what can be achieved with little formal or institutional support.

Increasingly, universities and colleges are offering courses in Indigenous languages, often in collaboration with the Indigenous communities on whose territory the institution is located. Across North America, language activists and teachers are developing curricula that adhere to the second-language requirements of their respective school districts. By developing curricula within these guidelines, courses may be eligible for second-language accreditation toward high school students' graduation language requirements. A case in point is the long-standing partnership between the Musqueam Indian Band and the First Nations and Endangered Languages Program (formerly the First Nations Languages Program) at the University of British Columbia in Vancouver. Initiated in 1997 as part of the university's commitment to community-based collaboration with First Nations peoples, the primary purpose of the partnership has been to promote the development and use of hən்q̇min’m, the Musqueam Central Coast Salish language, through collaborative research and teaching initiatives. In the nearly two decades since it began, this collaboration has produced several formal research papers, a series of elementary resource books, and a full complement of text and interactive online materials that support four levels of hə̉̇ł̇min̉əm language courses for post-secondary credit. These courses are open to both university and Musqueam students and serve as a powerful model for reconciliation. Another example is Six Nations Polytechnic, an Aboriginal-owned and -controlled post-secondary institution at Six Nations of the Grand River First Nation. The Polytechnic offers a three-year Bachelor of Arts in Ogwehoweh Languages in which Mohawk or Cayuga language and grammar are the core area of study, supplemented by courses in Indigenous history, culture and tradition, translation, ethno-astronomy, and ethno-botany. The strategic goal of the Bachelor of Arts in Ogwehoweh Languages is one of decolonization and self-determination: to further the continued development of Ogwehoweh cultural understanding within an Ogwehoweh language context.

In the United States, the first Indigenous language immersion school was founded in Hawai'i in 1983 by the non-profit 'Aha Pūnana Leo. The program offers early childhood education in Hawaiian and is the result of a sustained collaboration between the University of Hawai' $i$ and the wider community. The University of Hawai'i also offers graduate degree programs for students that are entirely in Hawaiian, and Hawaiian language theses are increasing in popularity in disciplines ranging from linguistics to history and literature. The impressive range of kindergarten to post-secondary graduate instruction makes the Hawaiian language revitalization effort one of the most comprehensive programs in the world and also ensures that the alumni of pünana leo early childhood education programs have more advanced programs through which they can further scaffold their education in Hawaiian should they choose to do so. The lack of such laddering plagues many other language revitalization programs: while there are often many resources available for beginner-level language learning, there is a dearth of material to engage more advanced speakers and adults. Ulukau, the Hawaiian Electronic Library, offers a creative solution. The online database and archive 
serves as a repository for a wide variety of materials designed for Hawaiian speakers of all levels, from beginner to advanced language competency. Along with dictionaries, curricula, and a collection of fiction and non-fiction literature, the site also hosts a compendium of Hawaiian-language newspapers published between 1834 and 1948. This remarkable online resource has many uses: it functions as a memory bank for over a century of Indigenous Hawaiian intellectual work and artistic creation, a way of supporting advanced speakers of Hawaiian who wish to further hone their reading skills, and a platform for engaging the now sizable Hawaiian diaspora who are looking for opportunities to connect with content in the Hawaiian language.

Initiatives like Ulukau fuse language revitalization with language documentation and cultural preservation. Documentation and revitalization have traditionally been thought of as quite separate and distinct endeavors, each with distinct goals that only occasionally intersect. Revitalization projects are usually defined as seeking to (re-)create fluency within a language community through the kinds of initiatives outlined above. Documentation, however, aims to describe a language in as much detail as possible for any number of different reasons, including future revitalization, curriculum development, cross-linguistic analysis, or simply for generating more complete scientific knowledge of humanity's linguistic diversity. A key element that helps to blur the line and bridge the divide between documentation and revitalization is the notion of access. Making documentation available via the Internet ensures that living speakers are afforded a way of engaging with the material that contributes to the goals of language revitalization. This blending of revitalization and documentation through digital availability is evidenced in many endangered language dictionary projects which make lexicographic materials available online or through mobile devices.

Mobile device applications have experienced massive growth in popularity over the past decade in tandem with the increasing ubiquity of smartphones. Apps vary considerably in terms of their functionality, accessibility, and stability. There are many bare-bones mobile phone apps offering minimal functionality (simply the option to browse through various words, for example), while others serve primarily as prestige tools - platforms without significant practical language learning or reference functionality that have been developed to engage younger people in the community and combat damaging stereotypes of Indigenous languages being "antiquated" or incompatible with modern technology. There are also, however, many apps that make use of audio, video, and sophisticated search algorithms to deliver a powerful and portable learning environment for language reclamation (Littell, Pine, \& Davis, 2017). While some apps are created as isolated projects by a specific language community, the Miromaa Aboriginal Language \& Technology Centre (MALTC) in Australia and the First People's Cultural Council (FPCC) in Canada are organizations committed to developing and maintaining apps for many different language communities around a common code base and shared technical infrastructure.

The FPCC, which also supports Mentor-Apprentice partnerships and produces regular reports on the status of First Nations languages in the province of British Columbia, released a keyboard app in May 2016 that supports unique language-specific characters to be typed on smartphones for over 100 languages, providing users with a way to text and search the web using their own orthography. Funded by the FPCC since 2000, a project entitled FirstVoices has developed a suite of web-based tools and services to support Aboriginal people engaged in language archiving, language teaching, and culture revitalization. The FirstVoices Language Archive contains thousands of text entries in many diverse Aboriginal writing systems, enhanced with sounds, pictures, and videos. A companion set of interactive online games was designed to present the archived FirstVoices language data in creative learning activities, and dictionary language apps have been developed for 13 First Nations language communities across the province of British Columbia. New platforms for digital dissemination such as these can help to enhance the quality and scope of more traditional language documentation work. For example, rather than situating the responsibility for adding missing words, making corrections and checking dialectal variation with the technical (and often non-Indigenous) "creators" of a dictionary, the community's involvement with and immediate use of digital resources for purposes of revitalization provides essential user feedback and community perspectives that improve both the accuracy and the utility of a lexicography project. Overall, new digital technologies are helping to foster increasingly collaborative forms of research that have the potential to be less hierarchical, more democratic, and better positioned to mobilize language resources within communities in multimodal ways that engage youth and elders alike.

While new technology has been leveraged to disseminate and democratize access to archives and collections, other efforts seek to achieve a similar impact in contexts where archival materials and historical collections are not so easily mobilized or transcoded. The U.S.-based National Breath of Life initiative facilitates informed community access to important documentary and archival resources. The project pairs community members with trained linguists who come together in Washington, D.C., to investigate and explore collections related to specific languages in 
some of the capital's most extensive libraries, including the Smithsonian Institution and the Library of Congress. Alongside promoting physical access to these unique collections, the involvement of a linguist as a partner can expedite the deciphering of heritage collections and support capacity development within the Indigenous research community. Based on the success of the National Breath of Life, a number of regional workshops across North America have been organized to help endangered language communities locate and mobilize language resources held in local archives and libraries.

The role of linguists in language documentation and revitalization projects has become more complex, contested, and political over time. Increasingly, partnerships between linguists and communities are founded and maintained on notions of mutual benefit, ethical engagement, respect, reciprocity, and trust. Yet there are also examples of partnerships that are far more controversial. Disagreements over the goals of the partnership (whether academic or community focussed, for example), intellectual property rights, authorship, accreditation, and compensation have resulted in strained and occasionally broken relationships between outside scholars and language communities. This tension has led to the suggestion that "sometimes no fieldwork on an endangered language is better than some" (Grinevald, 2003, p. 9), a statement that is antithetical to the established and conventional wisdom of standard documentary (what some scholars unapologetically refer to as "salvage") linguistics.

Explicitly addressing the skillset that a particular linguist brings to a community and what communities stand to gain from such a relationship are central to avoiding future conflict. Importantly, "good intentions are not sufficient to give good and useful results, and we must be selfreflective and self-critical about the sort of practices we engage in that unwittingly exacerbate rather than alleviate the problem" (Wilkins, 2000, p. 63). In some cases, communities have felt that their knowledge and voices have been used to advance the career of an outsider and caution others against inviting a linguist into their community. It has been poignantly noted that that there is a good chance an "outside linguist will learn your language, but your children won't." If language revitalization is to be a positive experience for all involved in the work-scholars from the outside and Indigenous scholars and knowledge keepers within language communities - deliberate and sometimes difficult discussions must be had which address the specific sociohistorical context that has resulted in the marginalization and endangerment of the language, the desired outcomes and tools for measuring success in revitalization, and the expectations that each party has of the other's involvement. Candor in such matters, as well as transparency in budgeting, remuneration, and ownership of resulting data, can help to establish a more equitable and ethical baseline for collaborative work in language revitalization.

While the alarms bells have sounded and the threat of languages ceasing to be spoken remains a reality for increasing numbers of communities, the indomitable human spirit in the face of adversity should not be underestimated. Language communities across the globe have proven throughout history that the odds can be beaten and that the effects of colonization are surmountable. Indigenous communities must be supported and resourced to design and implement their own research agendas, funding needs, and success criteria for language revitalization and reclamation work. Through engaging in collaborative linguistic and cultural revitalization work, building partnerships, communities of practice and resources at academic, governmental, and grassroots levels, the tide can be turned and more languages will join the ranks of Hawaiian, Māori, Myaamia, and Wampanoag.

\section{Further Reading}

Austin, P. (2008). 1000 languages. The worldwide history of living and lost tongues. London: Thames \& Hudson. Retrieved from http://eprints.soas.ac.uk/5576/.

[+] Find this resource:

Bradley, D., \& Bradley, M. (2013). Language endangerment and language maintenance: An active approach. London: Routledge.

[+] Find this resource:

Calvet, L. J. (1998). Language wars and linguistic politics. Oxford: Oxford University Press.

[+] Find this resource:

Carpenter, J., Guerin, A., Kaczmarek, M., Lawson, G., Lawson, K., Nathan, L. P., et al. (2016) Digital access for language and culture in First Nations communities. Ottawa: Social Sciences and Humanities Research Council of Canada. 
$[+]$ Find this resource:

Crystal, D. (2000). Language death. Cambridge, U.K.: Cambridge University Press.

[+] Find this resource:

Dalby, A. (2003). Language in danger: The loss of linguistic diversity and the threat to our future. New York: Columbia University Press.

[+] Find this resource:

Evans, N. (2011). Dying words: Endangered languages and what they have to tell us. Hoboken: John Wiley \& Sons.

$[+]$ Find this resource:

Fishman, J. A. (1991). Reversing language shift: Theoretical and empirical foundations of assistance to threatened languages. Clevedon, AVN, U.K.: Multilingual Matters.

[+] Find this resource:

Fishman, J. A. (2001). Can threatened languages be saved? Reversing language shift, revisited: A 21st century perspective. Buffalo: Multilingual Matters.

[+] Find this resource:

Hendriks, V., Janse, M., \& Tol, S. (2003). Language death and language maintenance: Theoretical, practical and descriptive approaches. Amsterdam: John Benjamins Publishing.

[+] Find this resource:

Hinton, L. (2013). Bringing our languages home: Language revitalization for families. Berkeley: Heyday.

[+] Find this resource:

Hinton, L., \& Hale, K. (2001). The green book of language revitalization in practice. San Diego: Academic Press.

$[+]$ Find this resource:

Hinton, L., Vera, M., \& Steele, N. (2002). How to keep your language alive: A commonsense approach to one-on-one language learning. Berkeley: Heyday.

[+] Find this resource:

Hobson, J. R. (2010). Re-awakening languages: Theory and practice in the revitalisation of Australia's Indigenous languages. Sydney: Sydney University Press.

[+] Find this resource:

Cash Cash, P. (2017). Indigenous languages and technology [Electronic mailing list]. Retrieved from http://www.u .arizona.edu/ cashcash/ILAT.html.

$[+]$ Find this resource:

Jones, M. C. (2014). Endangered languages and new technologies. Cambridge, U.K.: Cambridge University Press.

[+] Find this resource:

Nettle, D., \& Romaine, S. (2000). Vanishing voices: The extinction of the world's languages. New York: Oxford University Press.

$[+]$ Find this resource:

Pereltsvaig, A. (2012). Languages of the world: An introduction. Cambridge, U.K.: Cambridge University Press.

[+] Find this resource:

Shaw, P. A. (2001) Language and identity, language and the land. BC Studies, (131), 39-55. Vancouver: University of British Columbia Press. 
$[+]$ Find this resource:

Smith, L. T. (1999). Decolonizing methodologies: Research and Indigenous peoples. Dunedin: Zed Books.

[+] Find this resource:

\section{References}

Anchimbe, E. A. (2006). Functional seclusion and the future of indigenous languages in Africa: The case of Cameroon. In J. Mugane et al. (Eds.), Selected proceedings of the 35th annual conference on African linguistics (pp. 94-103). Somerville: Cascadilla Proceedings Project. Retrieved from http://citeseerx.ist.psu.edu/viewdoc/download?doi=10.1.1.497.4324\&rep=rep1\&type=pdf. doi:10.1.1.497.4324\&rep=rep1\&type $=$ pdf

[+] Find this resource:

Baldwin, D. (2003). Miami language reclamation: From ground zero. Lecture presented at the $24^{\text {th }}$ speaker series at the center for writing. University of Minnesota, Minneapolis. Retrieved from http://writing.umn.edu/lrs/assets/pdf/speakerpubs/baldwin.pdf.

$[+]$ Find this resource:

Barcant, A. (2013). Language and power! Convergence, 4, 46-54. Montreal: QPIRG Concordia and QPIRG McGill. Retrieved from http://convergencejournal.ca/archives/484.

[+] Find this resource:

Barnett, M., Seymour, M., \& Raine, E. (1975). Basic course in syllabic typing-keyboard. Ottawa: Deptartment of Indian Affairs and Northern Development.

[+] Find this resource:

Brenzinger, M., Yamamoto, A., Aikawa, N., Koundiouba, D., Minasyan, A., Dwyer, A., et al. (2003). Language vitality and endangerment. Paris: UNESCO Intangible Cultural Unit, Safeguarding Endangered Languages. Retrieved from http://www.unesco.org/culture/ich/doc/src/00120-EN.pdf.

[+] Find this resource:

Bulcha, M. (1997). The politics of linguistic homogenization in Ethiopia and the conflict over the status of "Afaan Oromoo." African Affairs, 96(384), 325-352. London: Royal African Society.

[+] Find this resource:

Cree Productions (Ed.). (1973). The teaching of the Cree language: Basic simplified method. Manitoba: Cree Productions.

[+] Find this resource:

Dobrin, L. M. (2009). SIL International and the disciplinary culture of linguistics: Introduction. Language, 85(3), 618-619. Washington: Linguistic Society of America.

[+] Find this resource:

Glass, A. (2004). Return to sender: On the politics of cultural property and the proper address of art. Journal of Material Culture, 9(2), $115-139$. Thousand Oaks: SAGE.

[+] Find this resource:

Grinevald, C. (2003). Speakers and documentation of endangered languages. Language Documentation and Description, 1, 52-72. London: The Hans Rausing Endangered Languages Project.

[+] Find this resource: 
Hallet, D., Chandler, M. J., \& Lalonde, C. E. (2007). Aboriginal language knowledge and youth suicide. Cognitive Development, (22), $392-399$. Norwood: Ablex.

[+] Find this resource:

Hingangaroa Smith, G. (2003). Kaupapa Māori theory: Theorizing indigenous transformation of education and schooling. Presented at Kaupapa Māori Symposium: NZARE/AARE Joint Conference. Auckland, NZ.

[+] Find this resource:

Hinton, L. (2001a). Sleeping languages: Can they be awakened? In L. Hinton \& K. Hale (Eds.), The green book of language revitalization in practice (pp. 411-417). Leiden, The Netherlands: Brill. Retrieved from

http://booksandjournals.brillonline.com/content/books/b9789004261723s032/?crawler=true\&mimetype=application/pdf.

[+] Find this resource:

Hinton, L. (2001b). The master-apprentice language learning program. In L. Hinton \& K. Hale (Eds.), The green book of language revitalization in practiceed (pp. 217-226). San Diego: Academic Press.

[+] Find this resource:

Hinton, L. (2013). Bringing our languages home: Language revitalization for families. Berkeley: Heyday.

[+] Find this resource:

Hinton, L. (2014). Orthography wars. In M. Cahill \& K. Rice (Eds.), Developing orthographies for unwritten languages (pp. 139-168). Dallas: SIL International.

[+] Find this resource:

Hinton, L. (2015, October). What counts as “success” in language revitalization? Future Speaker Series, University of British Columbia, Vancouver.

[+] Find this resource:

Hohepa, P. (1984). Current issues in promoting Maori language use. Language Planning Newsletter. Honolulu: East-West Center Institute of Culture and Communication. Retrieved from http://scholarspace.manoa.hawaii.edu/handle/10125/17570.

$[+]$ Find this resource:

Jensen, V., \& Powell, J. V. (1979). Learning Gitksan (Western Dialect, Books 1-4). Kitwancool, Kitsegukia, and Kitwanga Indian Bands. Unpublished manuscript.

[+] Find this resource:

Johnson, M. K. (2012). $\mathrm{k}^{\mathrm{w}} \mathrm{u}_{\smile} \mathrm{sq}^{\mathrm{w}} \mathrm{aPq}^{\mathrm{w}} \mathrm{a}$ ?álx (We begin to speak): Our journey within Nsyilxcn (Okanagan) language revitalization. Canadian Journal of Native Education, 35(1), 79-97, 222. Edmonton: University of Alberta.

$[+]$ Find this resource:

Kativik School Board. (1979). Northern Quebec Inuit language kit (Ungava dialect). Quebec: Commission Scolaire.

[+] Find this resource:

Kipp, D. R. (2000). Encouragement, guidance, insights, and lessons learned for native language activists developing their own tribal language programs. Browning: Piegan Institute's Cut-Bank Language Immersion School.

[+] Find this resource:

Krauss, M. (1992). The world's languages in crisis. Language, 68(1), 4-10. Washington: Lingusitic Society of America.

$[+]$ Find this resource: 
Lai, I., \& Ignace, M. (1998). A preliminary analysis of Secwepemc language acquisition by a young child. In 33rd international conference on Salish and neighboring languages (pp. 322-334). Retrieved from http://lingserver.arts.ubc.ca/linguistics/sites/default/files/1998_Lai_2.pdf.

$[+]$ Find this resource:

Leonard, W. Y. (2008). When is an "extinct language" not extinct? Sustaining linguistic diversity: endangered and minority languages and language varieties (pp. 23-33). Washington: Georgetown University Press.

[+] Find this resource:

Lewis, M. P., \& Simons, G. F. (2010). Assessing endangerment: Expanding Fishman's GIDS. Revue Roumaine de Linguistique, 2, $103-119$. Bucharest: Academiei Republicii Socialiste Romania.

$[+]$ Find this resource:

Lewis, M. P., Simons, G. F., \& Fennig, C. D. (2016). Ethnologue. Retrieved from https://www.ethnologue.com/.

[+] Find this resource:

Littell, P., Pine, A., \& Davis, H. (2017). Waldayu and Waldayu mobile: Modern digital dictionary interfaces for endangered languages. In Proceedings of ComputEL-2: The $2^{\text {nd }}$ Workshop on computational methods for endangered languages, ACL anthology. Philadelphia: University of Pennsylvania.

$[+]$ Find this resource:

Macaulay, T. B. (1835). Minute on Indian education, February 2, 1835. In G. Desai \& S. Nair (Eds.), Post-colonialisms: An anthology of cultural theory and criticism (pp. 121-131). Oxford: Berg.

[+] Find this resource:

Makepeace, A. (2010). We still live here: Âs Nutayuneân. IMDb. Retrieved from http://www.imdb.com/title/tt1754948/

$[+]$ Find this resource:

(1996). Maori: Growth in early childhood education. Statistics New Zealand. Retrieved from

http://www2.stats.govt.nz/domino/external/web/nzstories.nsf/3d7ba81fd31d11adcc256b16006bfcf3/babfd6ff89631735cc256b180003e067? OpenDocument

$[+]$ Find this resource:

Michif Languages Conference. (1985). The Michif languages project: committee report. Winnipeg: Manitoba Metis Federation.

$[+]$ Find this resource:

Morris, G. T. (2003). In R. Grounds, G. Tinker, \& D. Wilkins (Eds.), Vine Deloria Jr., and the development of a decolonizing critique of indigenous peoples and international relations (pp. 97-154). Native Voices: American Indian Identity and Resistance. Lawrence: University Press of Kansas.

$[+]$ Find this resource:

New Zealand Childcare Survey. (2010). Statistics New Zealand. Retrieved from

http://www.stats.govt.nz/browse_for_stats/people_and_communities/Children/ChildcareSurvey_HOTP2009revised/Correction.aspx.

$[+]$ Find this resource:

Olawsky, K. (2013). The master-apprentice language learning program down under: Experience and adaptation in an Australian context. Language Documentation \& Conservation, 7, 41-63. Honolulu: University of Hawaii Press. Retrieved from http://scholarspace.manoa.hawaii.edu/handle/10125/4569.

${ }^{[+}$Find this resource:

Olthuis, M.-L., Kivelä, S., \& Skutnabb-Kangas, T. (2013). Revitalising indigenous languages: How to recreate a lost generation (Vol. 10). 
Bristol: Multilingual Matters.

$[+]$ Find this resource:

Powell, J. V., Cook, M., Cranmer, A., \& Jensen, V. (1981). Learning Kwak’wala series (Vols. 1-13). Alert Bay, BC, Canada: U’mista Cultural Society.

[+] Find this resource:

Simon, J. A., \& Smith, L. T. (2001). A civilising mission? Perceptions and representations of the Native Schools system. Auckland: Auckland University Press.

[+] Find this resource:

Spolsky, B. (1995). Conditions for language revitalization: A comparison of the cases of Hebrew and Maori. Current Issues in Language \& Society, 2(3), 177-201. Clevedon: Multilingual Matters.

[+] Find this resource:

Statement by Prime Minister on release of the Final Report of the Truth and Reconciliation Commission. (2015, December 15). Prime Minister of Canada. Retrieved from http://pm.gc.ca/eng/news/2015/12/15/statement-prime-minister-release-final-report-truth-and-reconciliationcommission.

[+] Find this resource:

Sutherland, W. J. (2003). Parallel extinction risk and global distribution of languages and species. Nature, 423(6937), 276-279. London: Macmillan Journals.

[+] Find this resource:

Truth and Reconciliation Commission of Canada. (2015). Truth and reconciliation commission of canada: executive summary. Manitoba: Truth and Reconciliation Commission of Canada.

[+] Find this resource:

Turin, M. (2006). Minority language policies and politics in Nepal. In A. Saxena, L. Borin (Eds.), Lesser-known languages of South Asia: Status and policies, case studies and applications of information technology (pp. 61-72). Berlin: De Gruyter Mouton.

[+] Find this resource:

Watson-Gegeo, K. A. (1989). The Hawaiian language immersion program: Classroom discourse and children's development of communicative competence. Paper presented at the annual meeting of the National Council of Teachers of English. Baltimore, MD. Retrieved from http://eric.ed.gov/?id=ED321561.

$[+]$ Find this resource:

Whalen, D. H., Moss, M., \& Baldwin, D. (2016). Healing through language: Positive physical health effects of indigenous language use. F1000Research, 5, 852. London: F1000Research Ltd. doi:10.12688/f1000research.8656.1

[+] Find this resource:

Wilkins, D. P. (2000). Even with the best of intentions ... : Some pitfalls in the fight for linguistic and cultural survival (one view of the Australian experience). As lÍnguas Amazônicas hoje/Les Langues d'Amazonie Aujourd'hui, ed Queixalós, F., \& Renault-Lescure, O. São Paulo: Instituto Socioambiental.

[+] Find this resource:

Woolford, A. (2015). This benevolent experiment: Indigenous boarding schools, genocide, and redress in Canada and the United States. Lincoln: University of Nebraska Press.

$[+]$ Find this resource: 
Wurm, S., Muehlheausler, P., \& Laycock, D. (1977). Language planning and engineering in Papua New Guinea. New Guinea Area Language And Language Study, 3, 1157-1177. Canberra: Australian National University.

[+] Find this resource:

Zuckermann, G. 'ad, \& Walsh, M. (2011). Stop, revive, survive: Lessons from the Hebrew revival applicable to the reclamation, maintenance and empowerment of Aboriginal languages and cultures. Australian Journal of Linguistics, 31(1), 111-127. St. Lucia: Australian Linguistic Society.

[+] Find this resource:

\section{Notes:}

(1.) We follow the Canadian Federal Translation Bureau's capitalization guidelines.

(2.) "(1) never ask permission, never beg to save the language. Never; (2) never debate the issues. Never; (3) be very action oriented-just act; (4) show, don't tell; (5) use your language as your curriculum-botany, geography, political science, philosophy, history are all embedded in the language" (Kipp, 2000, p. 1).

\section{Aidan Pine}

University of British Columbia

\section{Mark Turin}

University of British Columbia

PRINTED FROM the OXFORD RESEARCH ENCYCLOPEDIA, LINGUISTICS (linguistics.oxfordre.com). (c) Oxford University Press USA, 2016. All Rights Reserved. Personal use only; commerc Privacy Policy and Legal Notice).

date: 11 April 2018

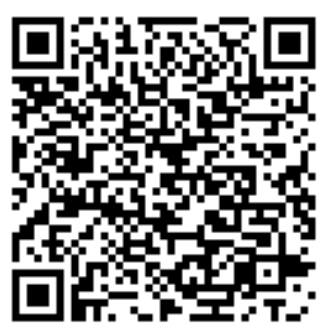

